\title{
Self-management interventions: Proposal and validation of a new operational definition
}

Nini H. Jonkma, Marieke J. Schuurmans, Tiny Jaarsma, Lillie M. Shortxidge-Baggett, Arno W. Hoes and Jaap C. A. Trappenburg

\section{Journal Article}

\section{Tweet}

N.B.: When citing this work, cite the original article.

Original Publication:

Nini H. Jonkma, Marieke J. Schuurmans, Tiny Jaarsma, Lillie M. Shortxidge-Baggett, Arno W. Hoes and Jaap C. A. Trappenburg, Self-management interventions: Proposal and validation of a new operational definition, JOURNAL OF CLINICAL EPIDEMIOLOGY, 2016. 80, pp.3442.

http://dx.doi.org/10.1016/j.jclinepi.2016.08.001

Copyright: Elsevier

http://www.elsevier.com/

Postprint available at: Linköping University Electronic Press

http://urn.kb.se/resolve?urn=urn:nbn:se:liu:diva-134090

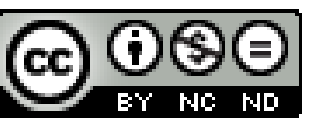


Self-management interventions: Proposal and validation of a new operational definition

Nini H. Jonkman, MSc $c^{\mathrm{a}}$ Marieke J. Schuurmans, RN PhD; ${ }^{\mathrm{a}}$; Tiny Jaarsma, RN PhD FAAN ${ }^{\mathrm{b}}$; Lillie M.

Shortridge-Baggett, EdD RN FAANc; Arno W. Hoes, MD PhD ${ }^{\text {; }}$ Jaap C.A. Trappenburg, PhD

\section{Author Affiliations:}

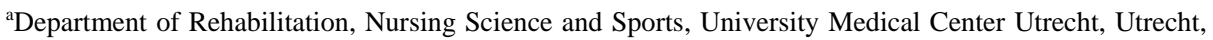
The Netherlands;

bDepartment of Social and Welfare Studies, Linköping University, Linköping, Sweden;

'Lienhard School of Nursing, College of Health Professions, Pace University, New York, NY;

dJulius Center for Health Sciences and Primary Care, University Medical Center Utrecht, Utrecht, The Netherlands.

\section{Corresponding Author:}

Nini H. Jonkman MSc

University Medical Center Utrecht

Department of Rehabilitation, Nursing Science \& Sports

HP W01.121

Heidelberglaan 100

3508 GA Utrecht

The Netherlands

Telephone: +31 613244760

Email: n.h.jonkman@vu.nl 


\section{Abstract}

Objectives: Systematic reviews on complex interventions like self-management interventions often do not explicitly state an operational definition of the intervention studied, which may impact the review's conclusions. This study aimed to propose an operational definition of self-management interventions and determine its discriminative performance compared to other operational definitions.

Study Design and Setting: Systematic review of definitions of 'self-management interventions' and consensus meetings with self-management research experts and practitioners.

Results: Self-management interventions were defined as "interventions that aim to equip patients with skills to actively participate and take responsibility in the management of their chronic condition in order to function optimally through at least knowledge acquisition and a combination of at least two of the following: stimulation of independent sign/symptom monitoring, medication management, enhancing problem-solving and decision-making skills for medical treatment management, and changing their physical activity, dietary and/or smoking behaviour.” This definition substantially reduced the number of selected studies (255/750). In two preliminary expert meetings $(n=6)$, the proposed definition was identifiable for self-management research experts and practitioners (resp. 80\% and 60\% agreement).

Conclusion: Future systematic reviews must carefully consider the operational definition of the intervention studied, since the definition influences the selection of studies upon which conclusions and recommendations for clinical practice are based.

Keywords: chronic disease, complex interventions, definition, self-management interventions.

Running title: Operationally defining complex self-management interventions.

Word count: 3131 
What is new?

\section{Key findings:}

- The choice of operational definition of 'self-management interventions' substantially influences the number and case-mix of self-management studies being selected.

What this adds to what is known:

- Questions regarding the effectiveness of self-management interventions are partly attributable to a lack of consensus about the definition of self-management interventions.

- This paper proposes a new operational definition of self-management interventions and provides an overview of current operational definitions of self-management interventions.

\section{What is the implication, what should change now:}

- Future systematic reviews on complex interventions must explicitly specify the operational definition of the studied intervention, since this defines the studies upon which recommendations for clinical practice are based. 


\section{Introduction}

There has been increasing attention for the challenges of synthesising and comparing the evidence on complex interventions[1,2]. Complex interventions are non-pharmacological interventions and generally consist of several interacting components[3]. Self-management interventions are an example of complex interventions and have evolved over the past decades into a central concept in care for patients with a chronic condition[4]. Patients with a chronic condition have contact with their healthcare providers only a fraction of their life, while nearly all patient outcomes are mediated through their daily behaviour[5]. Hence, targeting patients' self-management behaviour is currently considered a promising strategy for improving patient outcomes[6].

With the increasing enthusiasm, questions have emerged about the extent to which interventions to support patients' self-management are effective. The enormous number of studies conducted in this field[7] is accompanied by a subsequent increase in systematic reviews and meta-analyses that aim to provide an unambiguous answer about the effectiveness of self-management interventions. The metaanalyses repeatedly highlight the issue of the large heterogeneity among interventions included[8-11].

The way self-management interventions are defined determines the ultimate study selection from which conclusions in these systematic reviews and meta-analyses are drawn. Many studies give only a conceptual or general definition of self-management interventions, or no definition at all. The importance of clearly defining the complex intervention under study in a systematic review has been emphasised before[12]. Even with a general definition, only a straightforward operational definition of the complex intervention, clearly defining which components need to be present to meet the definition, will lead to a transparent selection process of interventions being studied or evaluated in research reports[12]. When the variety among self-management interventions is not taken into account and no clear operational definition is posited, this might lead to incorrect conclusions about the effectiveness of self-management interventions[13].

There is general agreement about the aspects included in a conceptual definition of self-management interventions. Self-management interventions should encompass more than solely a transfer of knowledge[5,13] and entail active involvement of patients to stimulate them taking responsibility in their plan of care[4,14]. This is often implemented by teaching patients self-monitoring and problem-solving 
skills to deal with aspects of their disease and optimise functioning[15]. Yet, the operationalisation of these self-management aspects for any specific study often remains unclear. Operationally defining selfmanagement interventions is a highly debated topic[8] as a gold standard of which essential elements constitute a self-management intervention is lacking[16]. Between different chronic conditions one can even see a difference in use of terminology. For example, in care for patients with chronic heart failure, 'self-care' is a term often used interchangeably with 'self-management' and relates to similar care processes of patients[17].

In an effort to define self-management interventions in an operational way, an international group of ten self-management research experts with a track record in the fields of chronic heart failure (CHF), chronic obstructive pulmonary disease (COPD), and type 2 diabetes mellitus (T2DM) set out to reach consensus during a conference meeting in the context of an individual patient data (IPD) meta-analysis on self-management interventions for chronic conditions[18]. Given the fact that a majority of chronic patients suffer from multiple conditions[19], self-management interventions were defined across chronic conditions to ensure optimal external validity:

"Self-management interventions aim to equip patients with skills to actively participate and take responsibility in the management of their chronic condition in order to function optimally through at least knowledge acquisition and a combination of at least two of the following: stimulation of independent sign/symptom monitoring, medication management, enhancing problem-solving and decision-making skills for medical treatment management, and changing their physical activity, dietary and/or smoking behaviour."

This operational definition is schematically presented in Fig. 1 and evolved from the assumption that management of medication use, independent symptom monitoring and health behaviours like diet, exercise and smoking are under the direct control of patients, subsequently those aspects of selfmanagement are often incorporated in self-management interventions[20]. Since current views highlight the multifaceted nature of self-management interventions[6,13], the focus is on interventions with 


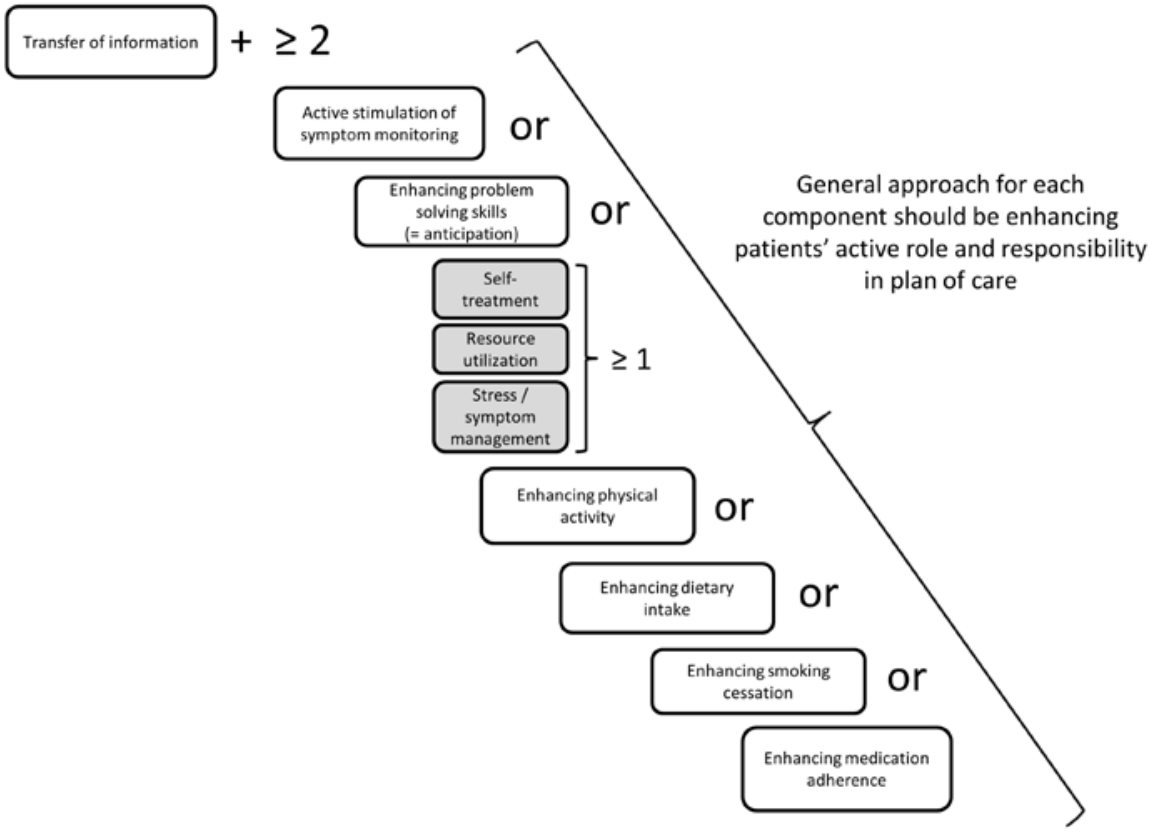

Fig. 1. Operationalisation of proposed definition for self-management interventions.

multiple $(\geq 2)$ components. This differentiates self-management interventions from interventions solely focusing on for instance exercise therapy or psychosocial therapies[11].

Expected subtle variations in operational definitions can result in substantial differences in case-mix of selected studies. A different case-mix of studies in a systematic review may influence the conclusions drawn and application of findings to clinical practice. The present study aimed to provide insight in the discriminative performance of the proposed definition to select self-management studies. Therefore, the operational definition was used to select studies meeting the definition. The resulting case-mix of studies was compared with the studies selected by other operational definitions of self-management interventions. In addition, the perceptions of self-management research experts and practitioners on self-management interventions was assessed. 


\section{Methods}

\subsection{Identifying operational definitions}

The electronic databases of Medline, EMBASE, CENTRAL, PsycINFO and CINAHL were searched from January 1985 through June 2013 to retrieve publications containing self-management definitions. Search terms were "self-management" in title/abstract combined with "chronic disease" as MeSH term or synonyms in title/abstract (Supplementary Material for the search syntax). Additionally, all Cochrane Systematic Reviews with "self-management" in title/abstract were added to the search results, as were relevant references in included publications.

Studies were screened on title/abstract by one researcher (N.H.J.) to select possible relevant publications. Full-texts were retrieved for studies that mentioned the term 'self-management' in either title or abstract. Full-texts were assessed to extract operational definitions of self-management interventions. Eligible studies were published in English and included an explicitly written operational definition of self-management interventions. Definitions were considered operational when selfmanagement interventions were defined in critical components that were needed to be present[12] to distinguish 'self-management' interventions from any other type of educational or behavioural interventions.

\subsection{Data extraction operational definitions}

From all operational definitions retrieved, we extracted the critical components of self-management interventions. Those were the components that were explicitly specified in the operational definitions and could be grouped according to: (1) providing knowledge about the condition/treatment; (2) anticipation skills for decisions about self-treatment/ professional attention; (3) independent monitoring of signs or symptoms; (4) dietary intake; (5) physical activity; (6) role management; (7) emotional coping; (8) medication management; (9) smoking cessation; and (10) miscellaneous. The selected operational definitions were categorised on similarities in critical components. Since the present study focused on self-management interventions across multiple chronic conditions for optimal external validity, from each category the study defining self-management interventions across multiple chronic conditions was 
selected for the comparison of definitions. If more definitions were generic, the definition published first was chosen.

\subsection{Identifying assumed self-management studies}

Published randomised trials on assumed self-management interventions were searched from January 1985 through June 2013 to assess whether the components in the evaluated interventions met the critical components of four operational definitions identified in the first step of this study. The randomised trials were acquired through a separate literature search previously conducted for an IPD meta-analysis[18] (Supplementary Material for the search syntax).

Studies were considered eligible if they (1) were reported in English, Dutch, French, German, Italian, Portuguese or Spanish; (2) were conducted in adult patients with a primary diagnosis of CHF, COPD and/or T2DM; (3) had a randomised trial design; and (4) consisted of an educational/behavioural intervention delivered to patients (i.e., not necessarily labelled ‘self-management').

\subsection{Assessing assumed self-management studies}

Four operational definitions of self-management interventions were compared. All assumed selfmanagement studies were scored on the presence of any of the critical components of the four operational definitions. Scoring of the intervention components was performed by one researcher (N.H.J.). A $10 \%$ random sample was assessed by a second researcher (J.C.A.T.) to judge consistency. With a Cohen's kappa of $\kappa=0.85(\mathrm{p}<0.01)$, a decision was made to perform the remaining data extraction for the operational definitions by one researcher (NHJ). Results are presented in numbers(\%). Since the present study focused on components of interventions without concern of their effectiveness, studies were not assessed on methodological quality. 


\subsection{Perceptions of self-management research experts and practitioners}

To compare the outcomes of the selection by the different operational definitions with the current perceptions of self-management research experts and practitioners, two meetings were organised following a general methodology of consensus diagnoses. Three self-management research experts (not involved in the conference meeting on developing the operational definition) from different institutes in the Netherlands with demonstrated experience in research regarding self-management in chronic disease attended one meeting (of six invited). Three practitioners who were currently working as general practitioner (1) or practice nurse (2) with chronic disease patients in different practices across the Netherlands attended the second meeting (of five invited). Prior to the meeting, each participant was asked to independently judge 20 intervention descriptions on whether the intervention was considered a self-management intervention based on his/her professional view. The intervention descriptions were the published texts of a random, blind selection of 20 trials from the systematic review. During the consensus meetings discrepancies and concerns were identified and based on an open discussion, individual judgments were discussed and as much as possible agreement was generated resulting in final consensus among the participants. An independent facilitator not involved in the present study led the discussions and made sure each individual expert contributed as much as possible to the discussions. Given the low numbers included, results were analysed descriptively and are presented as \% similarity in judgments made by research experts/practitioners. 
Table 1. Operational definitions of self-management interventions.

\begin{tabular}{|c|c|c|}
\hline Study & Condition(s) & Operational definition provided \\
\hline \multicolumn{3}{|l|}{ Multiple components } \\
\hline Present study ${ }^{*}$ & $\begin{array}{l}\text { Chronic heart } \\
\text { failure, COPD, } \\
\text { T2DM }\end{array}$ & $\begin{array}{l}\text { "Self-management interventions aim to equip patients with skills to actively } \\
\text { participate and take responsibility in the management of their chronic condition } \\
\text { in order to function optimally through at least knowledge acquisition and a } \\
\text { combination of at least two of the following: stimulation of independent } \\
\text { sign/symptom monitoring, medication management, enhancing problem-solving } \\
\text { and decision-making skills for medical treatment management, and changing } \\
\text { their physical activity, or dietary or smoking behaviour." }\end{array}$ \\
\hline $\begin{array}{l}\text { Bourbeau \& Van } \\
\text { der Palen, 2009[13] }\end{array}$ & COPD & $\begin{array}{l}\text { "Self-management interventions involve collaboratively helping patients acquire } \\
\text { and practice the skills needed to carry out disease-specific medical regimens, } \\
\text { change their health behaviour to adjust their roles for optimal function, improve } \\
\text { day-today control of their disease, and improve their well-being. Self- } \\
\text { management also includes assessment of progress and problems, goal setting, } \\
\text { and problem-solving." (p.461) }\end{array}$ \\
\hline \multicolumn{3}{|l|}{ Education plus } \\
\hline $\begin{array}{l}\text { Newman et al., } \\
2004[21]^{*}\end{array}$ & $\begin{array}{l}\text { Arthritis, Asthma, } \\
\text { T2DM }\end{array}$ & $\begin{array}{l}\text { "Interventions that directly target aspects of patients' management of chronic } \\
\text { illness...Interventions that only provided information in a didactic format or } \\
\text { manipulated delivery of information (e.g., assessment of telephone } \\
\text { consultations) were not included because provision of information alone has } \\
\text { been recognised as insufficient for improved self-management." (p.1523) }\end{array}$ \\
\hline \multicolumn{3}{|l|}{ Single component } \\
\hline $\begin{array}{l}\text { Barlow et al., } \\
2010[22]\end{array}$ & $\begin{array}{l}\text { Inflammatory } \\
\text { bowel syndrome }\end{array}$ & $\begin{array}{l}\text { "Interventions containing one or more components that are traditionally viewed } \\
\text { as enabling self-management (techniques to improve coping skills, strategies to } \\
\text { reduce anxiety or depression, cognitive-behavioral therapy, social support, } \\
\text { problem solving, maintaining self-report diaries, personal planning, goal-setting, } \\
\text { stress management, exercise, relaxation)." (p.12) }\end{array}$ \\
\hline $\begin{array}{l}\text { Chodosh et al., } \\
\text { 2005[8]* }\end{array}$ & $\begin{array}{l}\text { T2DM, } \\
\text { hypertension, } \\
\text { osteoarthritis }\end{array}$ & $\begin{array}{l}\text { "A systematic intervention that is targeted toward patients with chronic disease. } \\
\text { The intervention should help them actively participate in either or both of the } \\
\text { following: self-monitoring (of symptoms or of physiologic processes) or } \\
\text { decision making (managing the disease or its impact through self-monitoring)." } \\
\text { (p.428) }\end{array}$ \\
\hline $\begin{array}{l}\text { Fryer et al., } \\
\text { 2013[23] }\end{array}$ & Stroke & $\begin{array}{l}\text { "The intervention must contain at least one of the following components: } \\
\text { problem-solving, goal-setting, decision-making, self-monitoring, coping with the } \\
\text { condition or an alternative method designed to facilitate behaviour change and } \\
\text { improvements in physical and psychological functioning." (p.3) }\end{array}$ \\
\hline $\begin{array}{l}\text { Jovicic et al., } \\
2006[24]\end{array}$ & $\begin{array}{l}\text { Chronic heart } \\
\text { failure }\end{array}$ & $\begin{array}{l}\text { "The operational definition of self-management interventions included programs } \\
\text { aimed at enabling patients to assume responsibility for managing one or more } \\
\text { aspects of heart failure (e.g. symptom monitoring, weight monitoring, } \\
\text { medication dosage adjustment and/or decision-making)." (p.44) }\end{array}$ \\
\hline \multicolumn{3}{|c|}{ Social cognitive behavioural } \\
\hline $\begin{array}{l}\text { Bodenheimer, } \\
\text { 2003[27] }\end{array}$ & Generic & $\begin{array}{l}\text { "Has two components: (1) training in knowledge and technical skills related to a } \\
\text { specific chronic condition and (2) training, not condition-specific, in problem- } \\
\text { solving skills to assist in behavior change." (p.66) }\end{array}$ \\
\hline $\begin{array}{l}\text { Bodenheimer et al., } \\
\text { 2002[15]* }\end{array}$ & Generic & $\begin{array}{l}\text { "Two essential elements define self-management education: 1) Patients learn } \\
\text { problem-solving skills, useful at identifying problems from their own point of } \\
\text { view and using action plans to define solutions; and 2) these skills are applied to } \\
\text { three aspects of chronic illness: medical, social and emotional." (p.2472) }\end{array}$ \\
\hline Lorig, 2003[28] & Generic & $\begin{array}{l}\text { "Based on content drawn from both patients and professionals. This content } \\
\text { should focus on medical, role and emotional management. In addition, these } \\
\text { interventions enhance confidence through the use of patient-directed goal } \\
\text { setting, including feedback, modeling, reinterpretation of symptoms, and social } \\
\text { persuasion." (p.701) }\end{array}$ \\
\hline $\begin{array}{l}\text { Lorig \& Holman, } \\
\text { 2003[4] }\end{array}$ & Generic & $\begin{array}{l}\text { "Include content that addresses all three tasks: medical or behavioral } \\
\text { management, role management, and emotional management. Although most } \\
\text { health promotion and patient education programs deal with the medical and } \\
\text { behavioral management, most do not systematically deal with all three tasks." } \\
\text { (p.1) }\end{array}$ \\
\hline
\end{tabular}




\section{Results}

\subsection{Identifying operational definitions}

The search strategy and selection yielded 10 publications which contained an operational definition of self-management interventions (Fig. 2 for selection process). The resulting 10 operational definitions and the definition proposed above are presented in Table 1. Four categories of definitions with similar critical components could be identified in which the operational definitions were classified: (1) Multiple components (defining self-management interventions as requiring multiple components), with two operational definitions[13] including the one proposed in this study; (2) Education plus (defining selfmanagement interventions as more than just education), with one definition[21]; (3) Single component (defining self-management interventions as containing at least one specific component), with four operational definitions[8,22-24]; and (4) Social cognitive behavioural (defining self-management interventions as containing at least medical management, role management and emotional management, based on the framework of Corbin \& Strauss[25] and social cognitive theory[26]), with four definitions[4,15,27,28]. Four operational definitions have explicitly been built on an established theoretical framework[4,15,27,28] or authors referred to previous research to define essential components[8,23], whereas others did not explain how they came to defining which interventions constitute self-management and which do not[13,21,22,24]. From each category, the definition of selfmanagement interventions across multiple chronic conditions was used for the selection of selfmanagement trials (indicated with asterix in Table 1).

\subsection{Identifying and assessing assumed self-management studies}

We identified 750 randomised trials of behavioural interventions in patients with CHF, COPD or T2DM to which the four operational definitions were applied (Fig 2. for selection process). The impact of each definition on the number of selected studies is presented in Fig. 3 and the mixture of intervention components for each definition is presented in Table 2. Applying the criteria of the definition proposed in this study, the Multiple components definition, resulted in a substantial decrease of interventions compatible with the definition $(\mathrm{n}=255)$. This selection comprised interventions with a mixture of components (range 3-7), with independent monitoring of symptoms and anticipation skills being most 


\section{Selection of operational definitions}

\begin{tabular}{|c|}
\hline 126 duplicates \\
\hline 364 publications rejected \\
$\begin{array}{c}495 \text { publications } \\
\text { screened on title/ } \\
\text { abstract } \\
\text { retrieved }\end{array}$ \\
\hline
\end{tabular}

131 full-texts retrieved

\begin{abstract}
121 publications rejected:
43 self-management interventions undefined

41 definition not operational

17 focus not self-management intervention

11 specific type of interventions
\end{abstract}

9 using definition of others

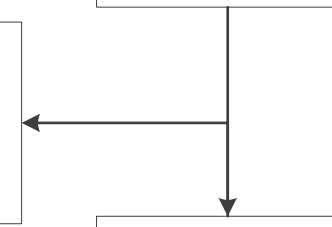

10 publications with

operational definition

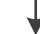

1 unpublished operational

definition

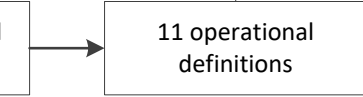

Operational definition

Multiple components

255 interventions

\section{Selection of self-management intervention}

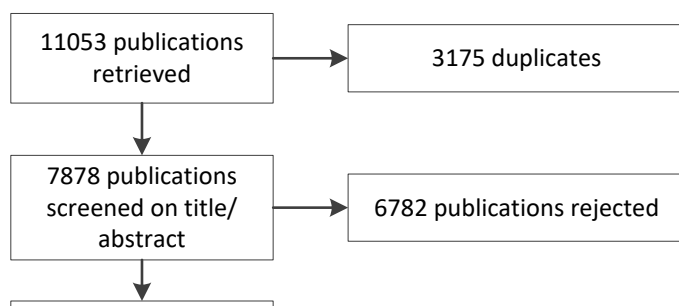

1096 full-texts

retrieved

Operational definition
Education plus

Education plus
545 interventions

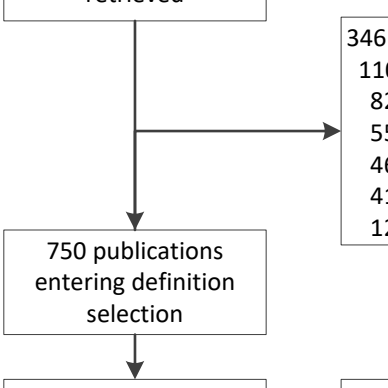

46 publications rejected:

no randomised controlled trial

82 no patients with $\mathrm{CHF} / \mathrm{COPD} / \mathrm{T} 2 \mathrm{DM}$

55 no structured behavioral intervention

46 no full-text available

41 language barrier

12 not targeted to patients

545 interventions

definitions selected

205 interventions not

selected by any defintion

Fig 2. Flowchart of selection of definitions and randomised trials of self-management interventions.

Abbreviation: $\mathrm{CHF}$, chronic heart failure; COPD, chronic obstructive pulmonary disease; T2DM, type 2 diabetes mellitus. 


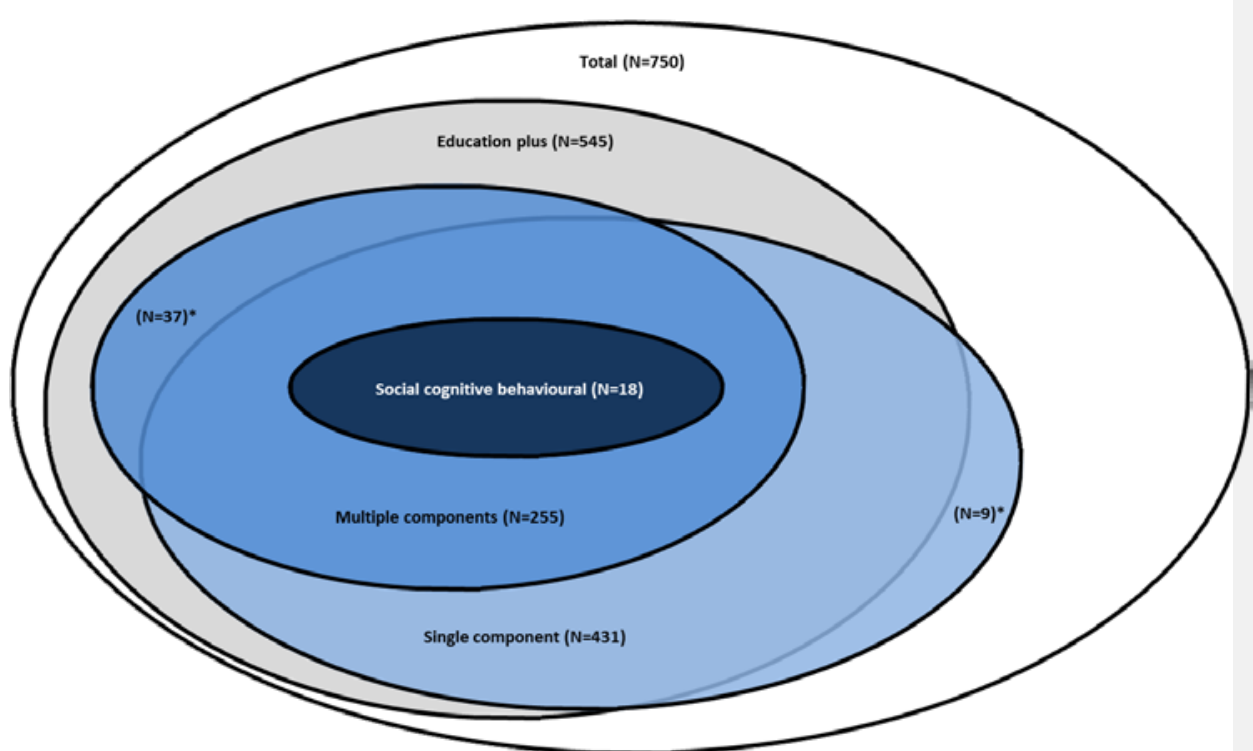

Fig. 3. Comparison of study selections by different operational definitions for self-management interventions.

* N=9 studies were selected by the Single component definition, but were not selected by the Education plus definition. N=37 studies were selected by the Multiple components definition, but were not selected by the Single component intervention.

often applied (in respectively 68\% and 65\% on the interventions). Applying the other definitions showed a gradual narrowing of the number of selected studies with increasing number of critical components. In the selection of Education plus ( $\mathrm{n}=545)$ all interventions comprised some form of knowledge provision, which was in half of the interventions accompanied by enhancing anticipation skills and/or independent monitoring of symptoms. The selection of the Single component definition $(\mathrm{n}=431)$ contained interventions which encompassed anticipation skills for decisions about treatment or skills for independent monitoring of symptoms. In $29 \%$ of the cases this was a combination of both. Fig. 3 shows that in nine interventions anticipation skills or independent monitoring were addressed without explicit education about the patient's condition. Thirty-seven interventions were selected by the Multiple components definition, but not by the Single component definition; these comprised a combination of dietary and physical activity interventions. In the selection by the Social cognitive behavioural definition all 18 interventions included education about the condition, role management and emotional coping with the condition, as required by this definition. The vast majority of the 18 interventions addressed 
1 Table 2. Case mix of studies selected by different operational definitions.

\begin{tabular}{|c|c|c|c|c|}
\hline Components & $\begin{array}{c}\text { Multiple } \\
\text { components } \\
(\mathrm{n}=255)\end{array}$ & $\begin{array}{c}\text { Education } \\
\text { plus } \\
(\mathbf{n}=545)\end{array}$ & $\begin{array}{c}\text { Single } \\
\text { component } \\
(n=431)\end{array}$ & $\begin{array}{c}\text { Social cognitive } \\
\text { behavioural } \\
(n=18)\end{array}$ \\
\hline $\begin{array}{l}\text { Providing knowledge about condition/ } \\
\text { treatment }\end{array}$ & $255(100.0)$ & $545(100.0)$ & $422(97.9)$ & $18(100.0)$ \\
\hline $\begin{array}{l}\text { Anticipation skills for decisions (about self- } \\
\text { treatment/ professional attention) }\end{array}$ & $167(65.2)$ & $273(50.1)$ & $280(65.0)$ & $16(88.9)$ \\
\hline $\begin{array}{l}\text { Independent monitoring of signs or } \\
\text { symptoms }\end{array}$ & $174(68.2)$ & 271 (49.7) & $274(63.6)$ & $8(44.4)$ \\
\hline Enhancing dietary intake & $136(53.3)$ & $175(32.1)$ & $100(23.2)$ & $13(72.2)$ \\
\hline Stimulation of physical activity & $103(40.2)$ & $135(24.8)$ & $66(15.3)$ & $8(44.4)$ \\
\hline Role management & $37(14.5)$ & $44(8.1)$ & $42(9.7)$ & $18(100.0)$ \\
\hline Emotional coping with condition & $28(10.9)$ & $42(7.7)$ & $39(9.0)$ & $18(100.0)$ \\
\hline Medication management & $31(12.1)$ & $39(7.2)$ & $25(5.8)$ & $1(5.6)$ \\
\hline Smoking cessation & $8(3.1)$ & $16(2.9)$ & $7(1.6)$ & $0(0.0)$ \\
\hline Miscellaneous (e.g., meditation skills) & $0(0.0)$ & $7(1.3)$ & $8(1.9)$ & $0(0.0)$ \\
\hline
\end{tabular}

anticipation skills (89\%) and dietary intake (72\%). The 205 interventions which were not selected by any

6 definition were either interventions solely providing knowledge about the disease or physical exercise

interventions without attention for behavioural skills.

\subsection{Perceptions of self-management research experts and practitioners}

In the random selection of the 20 interventions reviewed by self-management research experts and practitioners, the perceptions of what research experts considered to be self-management interventions

12 were most in line with the criteria applied by the more comprehensive definitions of Multiple components (80\%) and Social cognitive behavioural (65\%) (Table 3). The practitioners' perceptions corresponded mostly with the broader definitions of Single component (80\%) and Education plus (75\%). Combining the research experts and practitioners resulted in most agreement with the selection mechanism of the proposed definition (70\%).

Table 3. Agreement of perceptions research experts and practitioners with selection by definitions.

\begin{tabular}{|lccc|}
\hline Definition & All participants & $\begin{array}{c}\text { Self-management } \\
\text { research experts }\end{array}$ & $\begin{array}{c}\text { Self-management } \\
\text { practitioners }\end{array}$ \\
\hline Multiple components definition & $70 \%$ & $80 \%$ & $60 \%$ \\
\hline Education plus definition & $60 \%$ & $45 \%$ & $75 \%$ \\
\hline Single component definition & $65 \%$ & $50 \%$ & $80 \%$ \\
\hline Social cognitive behavioural definition & $50 \%$ & $65 \%$ & $35 \%$ \\
\hline
\end{tabular}



study. The Multiple components definition proposed in this paper resulted in a substantial reduction of eligible interventions that can be classified as self-management interventions (255/750) compared to the broader definitions of self-management interventions (545/750 and 431/750). The most restrictive

definition based on the Social cognitive behavioural resulted in a very small $(\mathrm{n}=18)$ and homogeneous selection of studies. The Multiple components definition best matched with current views of selfmanagement research experts (80\% agreement). The perceptions of practitioners about self-management interventions were most in line with definitions of self-management interventions as containing at least one component of behaviour change, instead of multiple components (80\% vs. 60\%).

Lorig and Holman[4] already emphasised the need to look beyond the label of 'self-management' to define if interventions actually address the necessary components. The results of the current study showed that a very strict and comprehensive definition as posited by authors of the Social cognitive behavioural definitions[4,15,27,28] will result in a homogeneous but restricted selection of interventions. The present findings showed that stricter definitions like the Multiple components or Social cognitive behavioural definitions narrowed down the study selection of broader definitions, with nearly a complete overlap in selected interventions. To avoid a premature exclusion of relevant interventions for clinical practice (99.9\% of all interventions was excluded with the strictest definition), one may choose to opt for a broader definition[8]. Yet, the heterogeneity among the included interventions with very broad definitions makes it questionable to what extent combining selected interventions is actually appropriate in a systematic review or meta-analysis and how an overall conclusion about the effectiveness of such diverse interventions can be transferred to practice[29]. This does not only apply to self-management interventions, but also to other types of complex interventions. These are critical points researchers should consider, since a different study selection might lead to different conclusions regarding effectiveness of complex interventions and subsequent recommendations for clinical practice.

Although the numbers of participants in the preliminary consensus meetings were relatively small, the results suggest that current perceptions of research experts regarding self-management interventions differed from those of practitioners. Overall, the research experts tended to judge more comprehensive 
interventions to be 'self-management interventions'. This is not surprising, since current scientific positions of what constitutes a self-management intervention address the multifaceted nature of these types of interventions[6,13] and research experts were likely well-informed of this scientific debate. Practitioners viewed interventions addressing only single aspects of behaviour change more often as selfmanagement interventions. Previous research has shown that practitioners consider provision of information as the principal component in their strategies for stimulating patients' self-management[30]. Their experience in providing self-management support to patients might have influenced with this less strict judgment. This discrepancy in perceptions highlights the need for a clear operational definition of self-management interventions to enhance communication with practice, particularly since healthcare providers continue to question the value of self-management support[31]. However, future research should assess if this difference between research experts and practitioners observed in the present study can be confirmed.

The operational definitions proposed and identified by the present study all focused on the content of interventions to set boundaries for what distinguishes self-management from any other form of education or behavioural intervention; none defined any criteria with regard to the intensity, duration or mode of delivery of the interventions. This is not surprising, as there is a continuum of strategies to apply selfmanagement interventions in practice[16]. Trying to restrict to a specific mode of delivery or intensity of a program would be counterproductive. Different types of patients might even respond better to or simply prefer specific modes of delivery.

This study has some limitations. First, study selection was based on the full-text description in publications of the interventions. In general, educational and behavioural interventions are inconsistently and incompletely described[32]. This might have led to more false-negative results (i.e., not selecting interventions due to incomplete description), particularly for the more comprehensive definitions. Second, although five to ten experts are considered adequate for content validation[33], and we included six experts, the proposed operational definition should be validated in a larger sample to confirm our findings. Additionally, this study has used an operational approach to define self-management interventions by scoring the separate components of the definitions. For the purposes of evaluating interventions, defining unambiguous criteria is highly important to be able to distinguish self- 
1

management interventions from other types of interventions[34]. Yet, self-management interventions are implemented in a dynamic setting involving a wide variety of patients and providers, making the actual intervention more than the sum of its separate components[35]. Third, this study has used the case of selfmanagement interventions to illustrate the importance of clearly defining the criteria for the complex intervention under study, However, the issues addressed in our study also apply to other types of complex interventions.

\section{Conclusion}

The present study proposed a new operational definition of 'self-management interventions', which can be used to make a distinct selection of self-management interventions without being too restrictive. In two preliminary expert meetings, the selection mechanism of the proposed definition was in line with current views of self-management research experts. Self-management practitioners judged less comprehensive interventions (i.e., those consisting of at least one behavioural component) to be 'selfmanagement interventions'. In view of the number of experts we included in our study, further validation of the proposed definition in al larger sample of scientific and clinical experts is needed. This study further highlights the need for future systematic reviews to carefully consider the operational definition of the intervention under study, since we showed that the operational definition substantially influences the selection of studies upon which conclusions and recommendations for clinical practice are based. 


\section{Acknowledgments}

2 We would like to thank Irene Bos-Touwen (University Medical Center Utrecht, Netherlands), Mary

3 Courtney (Australian Catholic University, Australia), Kathleen Dracup (University of California, San 4 Francisco, CA), and Thierry Troosters (Catholic University of Leuven, Belgium) for helping us to come 5 towards an operational definition of self-management interventions. This work was supported by the

6 Dutch Ministry of Health, Welfare and Sports, ZonMw grant number 520001002.

\section{Conflicts of interest}

9 None

\section{Role of the funding source}

12 This work was supported by the Dutch Ministry of Health, Welfare and Sports, ZonMw grant number 13 520001002. The funding source had no involvement in the design and conduct of the study; in collection, management, analysis, and interpretation of the data; in the writing of the report; and in the decision to submit the article for publication. 


\section{References}

[1] Petticrew M, Rehfuess E, Noyes J et al. Synthesizing evidence on complex interventions: how metaanalytical, qualitative, and mixed-method approaches can contribute. J Clin Epidemiol 2013;66:1230-43.

[2] Pigott T, Shepperd S. Identifying, documenting, and examining heterogeneity in systematic reviews of complex interventions. J Clin Epidemiol 2013;66:1230-43.

[3] Craig P, Dieppe P, Macintyre S, Michie S, Nazareth I, Petticrew M. Developing and evaluating complex interventions: the new Medical Research Council guidance. BMJ 2008;337:a1655.

[4] Lorig KR, Holman H. Self-management education: history, definition, outcomes, and mechanisms. Ann Behav Med 2003;26:1-7.

[5] Glasgow RE, Davis CL, Funnell MM, Beck A. Implementing practical interventions to support chronic illness self-management. Jt Comm J Qual Saf 2003;29:563-74.

[6] McGowan PT. Self-management education and support in chronic disease management. Prim Care 2012;39:307-25.

[7] Lu Y, Li Z, Arthur D. Mapping publications status and exploring hotspots in a research filed: chronic disease self-management. J Adv Nurs 2014:70;1837-44.

[8] Chodosh J, Morton SC, Mojica W et al. Meta-analysis: chronic disease self-management programs for older adults. Ann Intern Med 2005;143:427-38.

[9] Duke SA, Colagiuri S, Colagiuri R. Individual patient education for people with type 2 diabetes mellitus. Cochrane Database Syst Rev 2009;CD005268.

[10] Minet L, Moller S, Vach W, Wagner L, Henriksen JE. Mediating the effect of self-care management intervention in type 2 diabetes: a meta-analysis of 47 randomised controlled trials. Patient Educ Couns 2010;80:29-41

[11] Warsi A, Wang PS, LaValley MP, Avorn J, Solomon DH. Self-management education programs in chronic disease: a systematic review and methodological critique of the literature. Arch Intern Med 2004;164:1641-9.

[12] Squires JE, Valentine JC, Grimshaw JM. Systematic reviews of complex interventions: framing the research question. J Clin Epidemiol 2013;66:1215-22. 
[13] Bourbeau J, van der Palen J. Promoting effective self-management programmes to improve COPD. Eur Respir J 2009;33:461-3.

[14] Wagner EH. Chronic disease management: what will it take to improve care for chronic illness? Eff Clin Pract 1998;1:2-4

[15] Bodenheimer T, Lorig K, Holman H, Grumbach K. Patient self-management of chronic disease in primary care. J Am Med Assoc 2002;288:2469-75.

[16] Barlow J, Wright C, Sheasby J, Turner A, Hainsworth J. Self-management approaches for people with chronic conditions: a review. Patient Educ Couns 2002;48:177-87.

[17] Riegel B, Jaarsma T, Strömberg A. A middle-range theory of self-care of chronic illness. Adv Nurs Sci 2012;35:194-204.

[18] Jonkman NH, Westland H, Trappenburg JCA et al. Towards tailoring of self-management for patients with chronic heart failure or chronic obstructive pulmonary disease: a protocol for an individual patient data meta-analysis. BMJ Open 2014;4:e005220.

[19] Marengoni A, Angleman S, Melis R et al. Aging with multimorbidity: a systematic review of the literature. Ageing Res Rev 2011;10:430-9.

[20] Bodenheimer T, Wagner EH, Grumbach K. Improving primary care for patients with chronic illness. J Am Med Assoc 2002;288:1775-9.

[21] Newman S, Steed L, Mulligan K. Self-management interventions for chronic illness. Lancet 2004;364:1523-37.

[22] Barlow C, Cooke D, Mulligan K, Beck E, Newmann S. A critical review of self-management and educational interventions in inflammatory bowel disease. Gastroenterology Nursing 2010;33:11-8.

[23] Fryer CE, Luker JA, McDonnell MN, Hillier SL. Self-management programs for quality of life in people with stroke. Cochrane Database Syst Rev 2013;CD010442.

[24] Jovicic A, Holroyd-Leduc JM, Straus SE. Effects of self-management intervention on health outcomes of patients with heart failure: a systematic review of randomized controlled trials. BMC Cardiovasc Disord 2006;6:43.

[25] Corbin J, Strauss A. Unending Work and Care: Managing Chronic Illness at Home. San Francisco, LA: Jossey-Bass; 1988. 
1 [26] Bandura A. Health promotion by social cognitive means. Health Educ Behav 2004;31:143-64.

2 [27] Bodenheimer T. Interventions to improve chronic illness care: evaluating their effectiveness. Dis Manag 2003;6:63-71.

4 [28] Lorig K. Self-management education: more than a nice extra. Med Care 2003;41:699-701.

5 [29] Muhlhauser I, Berger M. Patient education - evaluation of a complex intervention. Diabetologia 2002;45:1723-33 Heart Lung 2012;41:583-93.

[31] Kennedy A, Rogers A, Bowen R et al. Implementing, embedding and integrating self-management support tools for people with long-term conditions in primary care nursing: A qualitative study. Int $\mathrm{J}$ Nurs Stud 2013;51:1103-13.

[32] Conn VS, Cooper PS, Ruppar TM, Russell CL. Searching for the intervention in intervention research reports. J Nurs Scholarsh 2008;40:52-9.

[33] Lynn MR. Determination and quantification of content validity. Nurs Res 1986; 35:382-385. 